in clinic before the patient is returned to the care of the GP, so longer prospective trials may help. It will also be important to establish the diagnosis of the patients, for with knowledge of the likely diagnostic categories and outcomes some rational scheme can surely be devised - perhaps in the form of guidelines on maintenance prescription of antidepressants in general practice-which may well help GPs to know just "how long" they can go on.

\section{Acknowledgement}

I am very grateful for the advice given to me by Professor P. McGuffin in writing of this paper.

\section{References}

British National Formulary, Number 17 (March 1989).

Catalan, J., Gath, Dh., Bond, A., Edmonds, G., Martin, P. \& ENNIS, J. (1988) General practice patients on longterm psychotropic drugs: A controlled investigation. British Journal of Psychiatry, 152, 399-406.

JoHnson, D. (1974) A study of the use of antidepressant medication in general practice. British Journal of Psychiatry, 125, 186-192.

Mindham, R. H. S., Bagshaw, A., Howard, C. \& SHEPHERD, M. (1975) An evaluation of continuation therapy with tricyclic antidepressants in depressive illness. Psychological Medicine, 3, 5-17.

TYRER, P. J. (1978) Drug treatment of psychiatric patients in general practice. British Medical Journal, ii, 1008-1010.

\title{
Medical audit quality of note-keeping
}

\author{
Aristos Markantonakis, Senior Registrar; and I. K. WeIR, Consultant in Child \\ Psychiatry, The Institute of Family Psychiatry, 23 Henley Road, Ipswich, \\ Suffolk IP1 3TF
}

Recently there has been an increasing awareness of the need for medical audit. Medical audit in the health service is not a new thing across the Atlantic. Many centres accept it as a normal part of health management. The findings of audit are made known to the individuals who have been audited with the aim that this would produce future improvement. Hence it is an effective way of increasing efficiency and highlighting inefficient and costly procedures. There is debate as to who should be doing the auditing. General practitioners have been suggested as being in the ideal position to be able to audit specialist services such as psychiatric services (Ferguson, 1990). GPs can be approached by questionnaire to gain their views as to the level of satisfaction on things such as communication, availability and usefulness of referral to a local specialist service (Markantonakis \& Mathai, 1990).

The quality of note-keeping by professionals in a department is very important. This importance is highlighted by the increasing amount of medico-legal work that is demanded from psychiatrists by courts. We are constantly reminded that medical notes can be referred to in court and that their accuracy can be of paramount importance. Child psychiatry has seen an increase in medico-legal work and an explosion in awareness and referral of cases of child abuse, physi- cal, emotional, and sexual. Who will be responsible for checking the quality of note-keeping? From our experience, constant reminders by the doctors to other professionals working on the multidisciplinary team is not sufficient to increase the quality of note keeping. Therefore we felt there was a need for a formal method of quality check.

\section{The questionnaire}

We devised a questionnaire asking seven questions which require a Yes or No answer. The questionnaire is easy to fill in and takes about five minutes to complete. The questions are designed to draw the attention of the note-keeper to the following points:

(1) The importance of providing a written entry in the notes after the first contact interview with a family or patient.

(2) The legibility of this entry.

(3) The importance of providing a 'formulation' in the case notes. The formulation should include a diagnosis or a clear description of the problem (everybody knows that ICD-10 and DSM-III$\mathbf{R}$ diagnoses are not easily provided by nondoctors) and secondly, the formulation should include a clear plan of management for the patient. 
(4) A check should be made in the notes of whether a letter has been sent to a referring agent after first contact. If a letter has not been sent to the GP, the GP will not know whether the patient has been seen.

(5) Whether any follow-up letters are sent to the referring agent. We know from our questionnaire to general practitioners that they requested more follow-up letters should be sent to them.

(6) A check as to whether all patient attendances are dated and entered in casenotes and, if so, when the last entry made should be recorded. This could be noted in terms of number of weeks on the checklist as a way of directing the note-keeper's attention to the length of time that has gone by without making an entry in the casenotes.

(7) A search should be made in the casenotes as to whether the patient attends a group for therapy and, if this is the case, whether attendances in the group are entered in the casenotes.

A space at the end of the form should be left for further comments. The present date and the date to be re-checked by the quality controller should also be entered on the form. Once completed the form can be photocopied, a copy can be kept in the notes, one sent to the professional dealing with the case and the third stored by the quality controller for reference in the future. This checklist sent to the notekeeper is a reminder of his quality of notekeeping. Also the result of all the checks can be sent periodically to all the members of the team to act as a further reminder of the importance of note-keeping.

The responsibility of quality controller can be shared between all the members of the multidisciplinary team. We felt this was important as we were hoping to encourage interest and enthusiasm in note keeping and to share this responsibility amongst everybody rather than for other professionals to see it imposed upon them by the medics.

\section{Findings}

Although this plan was discussed with other members of the multidisciplinary team, there has been a lack of enthusiasm by the non-doctor members of the team to carry out their responsibilities as acting as quality controller. The job has been left to the doctors on the team to complete the list and to send it to the note-keepers. However, we feel that there is a need for a constant reminder for individuals of the multi-disciplinary team to carry out their duty as quality controller in order that the checklist can have the desired effect of increasing the quality of notekeeping. Our initial feelings were that particular people were quite bad at note-keeping and needed constant reminders. However, most members of the team could see the value of this exercise as a means of protection against inadequate note-keeping. We felt that awareness about note-keeping generally was increased in the team. This was confirmed by a questionnaire sent to all members of the team asking for their feelings as to the usefulness of the questionnaire. Most members felt that their awareness of their note-keeping was increased and that they wanted the exercise continued. Also most felt that they could carry out the duties of quality controller with very little difficulty. There was still a need for constant reminders and the responsibility for this was taken by the doctors. However, we would like to compare our initial results at the start of the exercise with future checks, such as every six months, to assess the long-term effect. The questionnaire is available on request to $\mathrm{Dr}$
Markantonakis.

\section{References}

Ferguson, B. (1990) Clinical audit. A proposal. Psychiatric Bulletin, 14, 275-277.

MARKANTONAKIS, A. \& MathaI, J. (1990) Evaluation of the level of knowledge and satisfaction by general practitioners of a local child and family psychiatric service. Psychiatric Bulletin, 14, 328-329. 